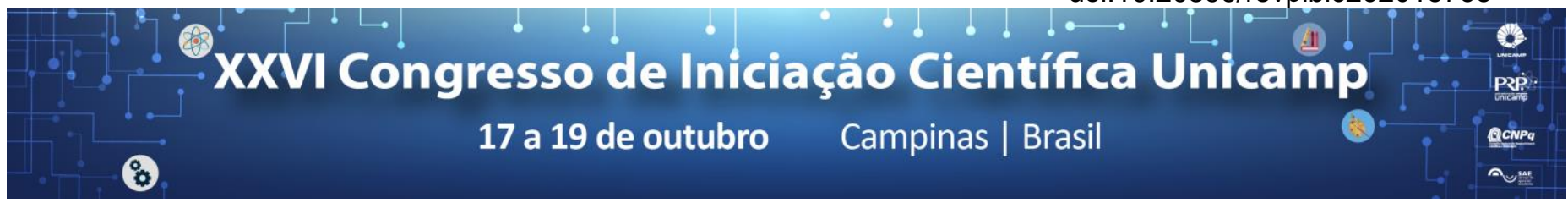

\title{
Caracterização da venação e superfície foliar como subsídio à taxonomia de Vismia Vand. (Hypericaceae)
}

\section{Katemann A. V. Uemoto*, Milena V. Martins, Gustavo H. Shimizu, Volker Bittrich \& Maria do Carmo E. do Amaral.}

\section{Resumo}

Popularmente conhecido como lacre, Vismia (Hypericaceae) é um gênero relativamente pouco estudado e que necessita de investigações detalhadas sobre caracteres diagnósticos que permitam distinguir suas espécies. No âmbito dos estudos morfológicos e taxonômicos em curso sobre o gênero, o presente trabalho teve como objetivos analisar e caracterizar a venação e a superfície foliar de 12 espécies de Vismia, utilizando, respectivamente, microscopia óptica de folhas diafanizadas e microscopia eletrônica de varredura. Foram encontrados três padrões gerais de venação foliar e diferenças significativas em relação ao tipo de indumento, que auxiliam na separação de grupos dentro do gênero.

\section{Palavras-chave:}

Arquitetura foliar, epiderme foliar, sistemática vegetal.

\section{Introdução}

As espécies de Vismia são morfologicamente muito parecidas, o que dificulta sua identificação. O estudo das nervuras e das superfícies foliares pode auxiliar o reconhecimento de espécies de plantas. O objetivo do presente trabalho foi caracterizar a venação foliar, através de microscopia óptica de folhas diafanizadas, e investigar caracteres da superfície foliar, através de microscopia eletrônica de varredura (MEV). Foram estudadas 12 espécies de Vismia escolhidas para contemplar as três seções do gênero estabelecidas por Reichardt $(1878)^{1}$ com base no número de estames por fascículo e número de óvulos por lóculo do ovário.

\section{Resultados e Discussão}

Foram encontrados três padrões gerais de venação foliar: A, B e C (Fig. 1), sendo o último particular de Vismia tenuinervia, separando-a facilmente das demais espécies analisadas.
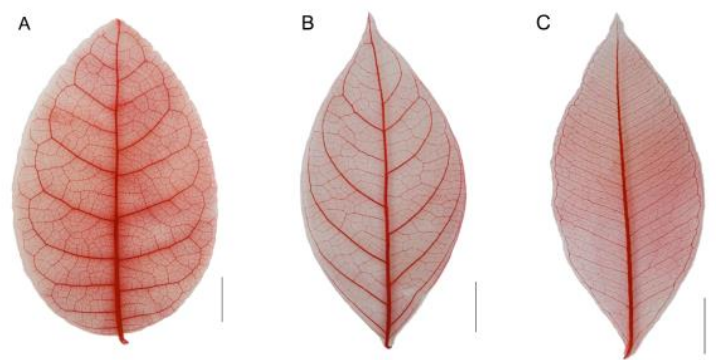

Figura 1. Padrões de venação em folhas diafanizadas. A. Broquidódromo: Vismia brasiliensis. B. Camptódromo na região basal, tornando-se broquidódromo no ápice: Vismia guianensis. C. Broquidódromo com formação de nervura intramarginal: Vismia tenuinervia. Barra $=1 \mathrm{~cm}$.

Pontuações nigrescentes foram observadas em quase todas as folhas diafanizadas das espécies estudadas, com exceção de Vismia guianensis. Vismia brasiliensis e $V$. macrophylla apresentaram, além das pontuações nigrescentes, pontuações translúcidas esbranquiçadas. Vismia brasiliensis é a única espécie que apresentou como padrão uma pontuação nigrescente em cada curvatura da margem levemente crenada.

Vismia cayennensis foi a única das espécies de Vismia estudadas que apresentou folhas com ambas as superfícies (abaxial e adaxial) glabras sob a microscopia óptica. As outras espécies apresentaram a superfície adaxial glabrescente e a abaxial com tricomas dendríticos e/ou estrelados. Vismia guianensis, $V$. japurensis e $V$. magnolifolia exibiram uma densa cobertura de tricomas estrelados (acima de 50 tricomas no campo visual em aumento de 100X). Vismia brasiliensis, $V$. cayennensis, $V$. guianensis, $V$. japurensis, $V$. magnoliifolia e $V$. sandwithii apresentaram tricomas estrelados, tufosos e sésseis, enquanto que em Vismia cauliflora, $V$. macrophylla e $V$. micrantha, os tricomas observados foram do tipo dendrítico, com a base alongada e maior do que o corpo. Com o auxílio de microscopia eletrônica de varredura foram visualizados tricomas que nem sempre puderam ser observados através de microscopia óptica. Em Vismia cayennensis, foram observados com MEV pequenos e esparsos tricomas (entre 20 e 50 no campo visual em aumento de 100X) que não foram visualizados em microscopia óptica. Foram observados estômatos apenas na superfície abaxial das espécies analisadas.

\section{Conclusões}

Com base nos dados obtidos, foi possível separar as espécies estudadas em três padrões de venação foliar, além de apontar diferenças significativas no indumento foliar. Possivelmente, estudos anatômicos e histoquímicos também poderão trazer contribuições relevantes para permitir o reconhecimento das espécies do gênero.

\section{Agradecimentos}

\section{CAPES, CNPq/MCTI/FAP - PROTAX, FAPESP.}

\footnotetext{
Reichardt, H.W. Hypericaceae. In: Martius, C.F.P.; Eichler, A.W. e Urban, I. (Eds.). Flora brasiliensis. 1878, vol. 12, part 1, pp. 182-212.
} 